O Open Access Full Text Article

\title{
Impacts of Different Spirometry Reference Equations and Diagnostic Criteria on the Frequency of Airway Obstruction in Adult People of North China
}

This article was published in the following Dove Press journal: International Journal of Chronic Obstructive Pulmonary Disease

\author{
Mengshuang Xie $\mathbb{D}$ \\ Liwei Cui $\mathbb{D}$ \\ Jinhuan Liu \\ Wei Wang (D) \\ Jun Li \\ Wei Xiao
}

Department of Pulmonary and Critical Care Medicine, Qilu Hospital, Shandong University, Jinan, People's Republic of China
Correspondence: Wei Xiao Department of Pulmonary and Critical Care Medicine, Qilu Hospital, Shandong University, 107 Wenhua West Road, Jinan 2500 I2, People's Republic of China $\mathrm{Tel} / \mathrm{Fax}+8653182166294$

Email xiaowei4226@163.com
Background and Objective: The reference equations and diagnostic criteria play a critical role in the interpretation of pulmonary function tests (PFTs). The aim was to investigate the impacts of different reference equations and diagnostic criteria on the frequency of airway obstruction in adult people of a large teaching hospital of North China.

Methods: The spirometry data of all adult people who underwent PFTs in Qilu hospital from April 2012 to November 2015 were collected. Two spirometry reference equations, namely, Zhongshan-2011 and Global Lung Function Initiative 2012 (GLI-2012) were compared. The frequency of airway obstruction using different spirometry prediction equations and diagnostic criteria including forced expiratory volume in $1 \mathrm{~s}$ (FEV1)/forced vital capacity (FVC) $<92 \%$ of predicted value and FEV1/FVC <lower limits of normal (LLN) were investigated.

Results: A total of 57,888 subjects were recruited with a mean age of $55.5 \pm 13.72$. There were significant differences in LLN and predicted value between the GLI-2012 and Zhongshan-2011. The average age of those who had an LLN of FEV1/FVC below 0.7 was $66.59 \pm 6.05$ years using GLI-2012, which was significantly lower than that in Zhongshan-2011 (77.46 $\pm 2.63, \mathrm{P}<0.001)$. Using FEV1/FVC $<$ LLN as diagnostic criteria, Zhongshan-2011 identifies more obstructive subjects than GLI-2012 in each age group. In 45-59 or 60-80 age group, more participants were defined as obstructive using FEV1/FVC $<92 \%$ pred than FEV1/FVC $<$ LLN (both $\mathrm{P}<0.001$ ). Conclusion: Zhongshan-2011 identifies more airway obstruction than GLI-2012 in adult people of North China. Compared to FEV1/FVC $<$ LLN, FEV1/FVC $<92 \%$ pred may lead to overdiagnosis of airway obstruction in elderly people.

Keywords: lung function, LLN, airflow limitation, reference equations, COPD

\section{Introduction}

Airway obstruction is caused by an increase in airway resistance when intrathoracic or extrathoracic narrowing of the airway leads to a reduction of airflow. Airway obstruction is one of the main characteristics of obstructive lung diseases including asthma and chronic obstructive pulmonary disease (COPD). ${ }^{1,2}$ Spirometry is the most commonly used method for the diagnosis of airway obstruction. Among the parameters of spirometry, the ratio of forced expiratory volume in $1 \mathrm{~s}$ (FEV1) to forced vital capacity (FVC) is the most widely accepted indicator of airway obstruction. The reduction of FEV1/FVC generally indicates the presence of airway obstruction. ${ }^{3}$

Although pulmonary function tests (PFTs) have been widely used for decades, there are still some difficult issues in the accurate interpretation of PFTs and 
diagnosis of airway obstruction. One of the problems is the controversial diagnostic criteria. In the diagnosis of airway obstruction, there is still a controversy regarding the appropriate cut-off values for FEV1/FVC. FEV1/FVC < lower limits of normal (LLN) are accepted by various guidelines on PFTs such as American Thoracic Society (ATS)/European Respiratory Society (ERS) interpretative strategies for lung function tests. ${ }^{4}$ In China, FEV1/ FVC $<92 \%$ of predicted value is also recommended by the guidelines for PFTs published by Chinese Thoracic Society. ${ }^{5}$ Fixed cut-off such as FEV1/FVC $<0.7$ is accepted as the definition of airflow limitation by Global Initiative for Chronic Obstructive Lung Disease (GOLD). ${ }^{6}$

Reference equations also play an important role in the correct interpretation of PFTs. The interpretation of PFTs is usually dependent on the comparisons of data measured in an individual patient or subject with reference values deriving from the epidemiological data of healthy subjects. ${ }^{4}$ Using different lung function reference equations may influence the interpretation of PFTs results. There are two widely accepted reference equations for adult people of North China: the reference equations published by Zhongshan hospital (Zhongshan-2011) ${ }^{7}$ and Global Lung Function Initiative 2012 equations (GLI-2012) for northeast Asians. ${ }^{8}$ Zhongshan hospital is one of the earliest hospitals which carry out PFT in China and the Zhongshan-2011 reference equations are widely used in Northern and Eastern China. The GLI-2012 are multi-ethnic reference equations for spirometry for the 3-95-yr age range. ${ }^{8}$ GLI-2012 were developed for four specific populations: Caucasian, Black, North-East Asian and South-East Asian and were intended to be applied globally. ${ }^{8}$ Previous studies showed that the applicability of GLI-2012 was different in different countries or populations. ${ }^{9-14}$ However, the values of GLI-2012 in North Chinese have not been fully investigated yet.

In clinical practice, the presence of different reference equations and/or diagnostic criteria causes great difficulties for the accurate interpretation of PFTs. The aim of this study was to investigate the impacts of different reference equations and diagnostic criteria on the frequency of airway obstruction in adult people of a large teaching hospital of North China.

\section{Population and Methods Study Population}

The study was conducted in accordance with the Declaration of Helsinki, national and institutional standards. ${ }^{15}$ The study was approved by the Ethics Committee of Qilu Hospital of
Shandong University (No 2015091). To preserve the participants' privacy and data confidentiality, the participants' data have been identified before analysis. All analyses in this retrospective study were performed based on the data from anonymized patients. Due to the non-interventional retrospective nature of this study, the Ethics Committee of Qilu Hospital of Shandong University approved an informed consent waiver for the retrospective medical record review.

The data were collected from a database that contained all the adult patients' PFTs data of Qilu hospital, one of the top medical centers in North China, between April 2012 and November 2015. The database includes 70,513 subjects who underwent PFTs, including patients with pulmonary diseases, people who underwent health examinations and patients who underwent preoperative examination. The inclusion criteria were: 1) age between 18 and 80 years; 2) PFTs that fulfil ATS/ERS guidelines of lung function tests. $^{4,16}$

\section{Pulmonary Function Tests}

All PFTs were performed on computerized spirometers (Masterscreen, Jaeger, Hochberg, Germany) according to the ATS/ERS recommendations. ${ }^{4,16}$ Each spirometer was calibrated daily using a syringe of $3 \mathrm{~L}$ volume. A minimum of three satisfactory slow and forced vital capacity manoeuvers were required of each subject. All the data of PFTs enrolled in this study were measured without the use of bronchodilators. The Basic information involving age (year), height $(\mathrm{m})$, weight $(\mathrm{Kg})$, body mass index (BMI; $\mathrm{Kg} / \mathrm{m}^{2}$ ) were collected before PFTs. Spirometry parameters including FEV1 [L], FVC (L), FEV1/FVC (\%) and vital capacity $(\mathrm{VC} ; \mathrm{L})$ were collected.

\section{Calculation of Predicted Value and LLN}

The predicted values and LLN of FEV1, FVC and FEV1/ FVC were derived using prediction equations from the GLI2012 (North-East Asian) and Zhongshan-2011. ${ }^{7,8}$ The prediction equations include sex, age, height and weight. The impacts of different reference equations and diagnostic criteria on the frequency of airway obstruction in adult people of a large teaching hospital of North China. Those participants with pre-bronchodilator FEV1/FVC lower than cut-off values were termed as airway obstruction. The cut-off values of FEV1/FVC were calculated using two different reference equations (Zhongshan-2011 and GLI-2012) and two diagnostic criteria (LLN and 92\% predicted). 


\section{Statistical Analysis}

Statistical analyses were performed using SPSS version 19.0 (IBM Corporation, Armonk, NY, USA) and Medcalc version 15.2 (MedCalc Software, Ostend, Belgium). Demographic and clinical characteristics of all subjects were summarized descriptively. Quantitative data were expressed as mean and standard deviation (SD). The normality assumption was tested through the kolmogorov-smirnov test. The independent samples and paired t-tests were used to test group differences of normally distributed data and chisquare test was used to compare classified variables. The differences of predicted values of spirometry parameters between two prediction equations were evaluated using Bland-Altman plot. Correlation between the measurements was calculated with the Pearson correlation coefficient. A P-value less than 0.05 was considered statistically significant.

\section{Results}

\section{Participants' Characteristics}

A total of 12,625 subjects were not included and 57,888 subjects met the selection criteria (Figure 1). The mean age was $55.5 \pm 13.72$ and 33,677 (58.18\%) were males. The participants were divided into three groups: age 18-44, age 45-59 and age 60-80 according to the global burden of disease study $2000 .{ }^{17}$ The basic characteristics of the participants are shown in Table 1.

\section{The Comparison Between Two Reference Equations}

The predicted value between the two versions of reference equations are compared in Table 2. The LLN and predicted FEV1/FVC from Zhongshan-2011 was higher than that from GLI-2012. The LLN and predicted FVC from Zhongshan-2011 was lower than that from GLI2012. The trends of FEV1/FVC and FVC were same in

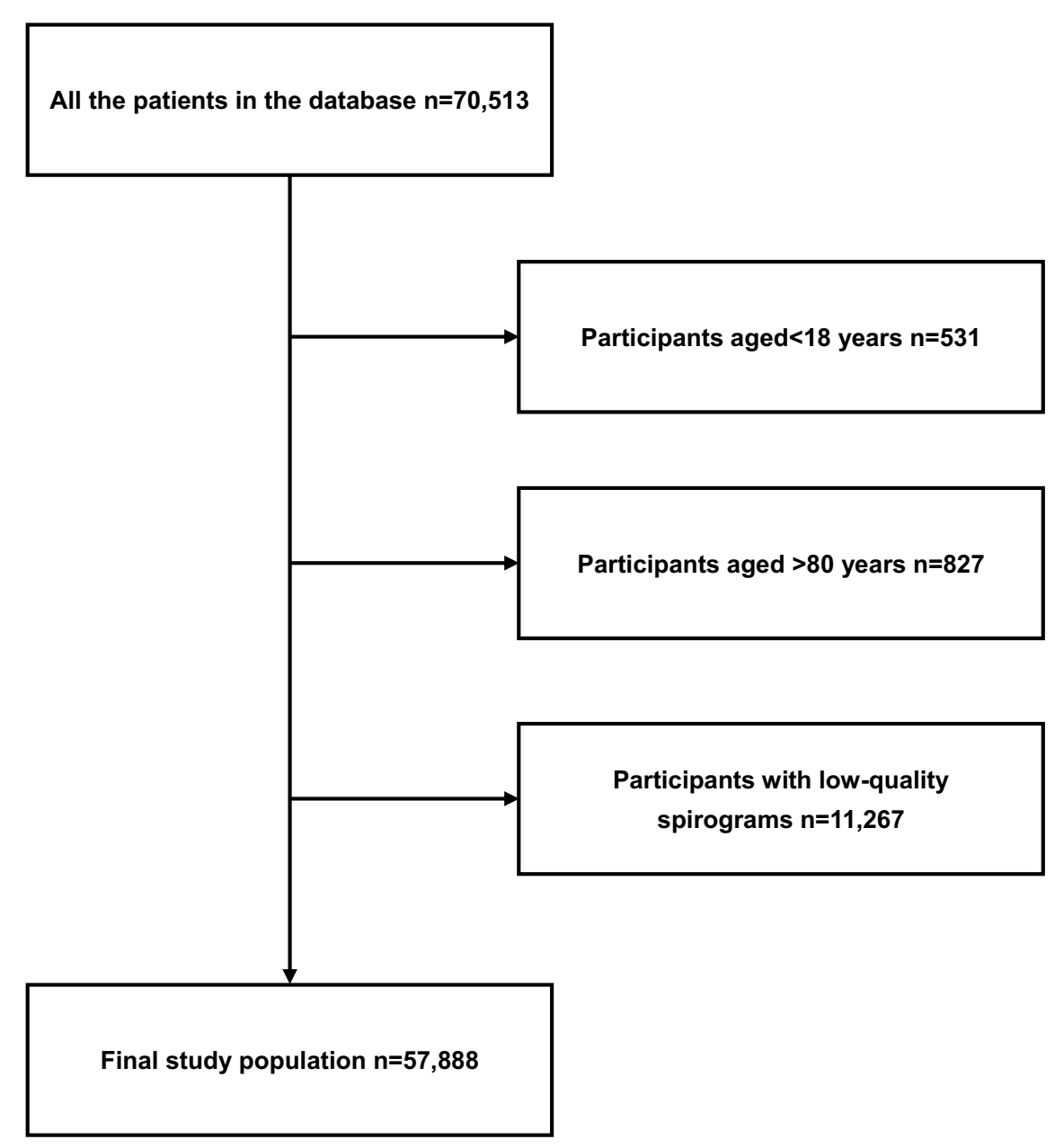

Figure I Flowchart of the selection of the study population. 
Table I Participants' Spirometric and Anthropometric Characteristics

\begin{tabular}{|l|l|l|l|l|}
\hline & Total & Age 18-44 & Age 45-59 & Age 60-80 \\
\hline Subjects, $\mathrm{n}$ & 57,888 & 12,134 & 19,977 & 25,777 \\
Age, years & $55.50 \pm 13.72$ & $34.65 \pm 7.20$ & $52.75 \pm 4.37$ & $67.45 \pm 5.50$ \\
Sex (male, \%) & 58.18 & 48.82 & 56.01 & 64.26 \\
Height, cm & $163.37 \pm 8.17$ & $165.17 \pm 8.38$ & $163.52 \pm 7.97$ & $162.4 I \pm 8.07$ \\
Weight, kg & $65.90 \pm 12.29$ & $66.65 \pm 13.95$ & $66.92 \pm I I .76$ & $64.76 \pm I I .75$ \\
BMI, kg/m & $24.64 \pm 3.93$ & $24.33 \pm 4.18$ & $24.98 \pm 3.75$ & $24.52 \pm 3.92$ \\
FEVI, L & $2.36 \pm 0.87$ & $2.98 \pm 0.84$ & $2.44 \pm 0.81$ & $2.00 \pm 0.73$ \\
FVC, L & $3.14 \pm 0.94$ & $3.74 \pm 0.95$ & $3.26 \pm 0.88$ & $2.78 \pm 0.80$ \\
VC, L & $3.26 \pm 0.93$ & $3.82 \pm 0.94$ & $3.37 \pm 0.88$ & $2.92 \pm 0.80$ \\
FEVI/FVC & $0.7397 \pm 0.1354$ & $0.7959 \pm 0.1086$ & $0.7415 \pm 0.1312$ & $0.718 I \pm 0.1414$ \\
\hline
\end{tabular}

Note: Data are presented as mean \pm standard deviation and $\mathrm{n}$ or $\mathrm{n}(\%)$

Abbreviations: BMI, Body Mass Index; FEVI, forced expiratory volume in I s; FVC, forced vital capacity; VC, vital capacity.

males and females. The predicted value of FEV1 from Zhongshan-2011 was higher in males and lower in females compared to that from GLI-2012. The LLN of FEV1 from Zhongshan-2011 was lower in males and higher in females compared to that from GLI-2012. The difference was $0.15 \mathrm{~L}$ in FVC and $0.01 \mathrm{~L}$ in FEV1 between two reference equations.

Table 2 The Comparison Between Zhongshan-20I I and GLI-20I2 Reference Values

\begin{tabular}{|c|c|c|c|}
\hline & Zhongshan-20II & GLI-20I2 & P-value \\
\hline FEVI pred, L & $2.85 \pm 0.58$ & $2.84 \pm 0.59$ & $<0.001$ \\
\hline Males & $3.19 \pm 0.41$ & $3.13 \pm 0.52$ & $<0.001$ \\
\hline Females & $2.36 \pm 0.41$ & $2.45 \pm 0.43$ & $<0.001$ \\
\hline FVC pred, L & $3.40 \pm 0.70$ & $3.55 \pm 0.71$ & $<0.001$ \\
\hline Males & $3.85 \pm 0.45$ & $3.94 \pm 0.58$ & $<0.001$ \\
\hline Females & $2.76 \pm 0.44$ & $3.00 \pm 0.46$ & $<0.001$ \\
\hline FEVI/FVC pred & $0.8177 \pm 0.0253$ & $0.8020 \pm 0.0253$ & $<0.001$ \\
\hline Males & $0.8 \mid I 2 \pm 0.0233$ & $0.7927 \pm 0.0225$ & $<0.001$ \\
\hline Females & $0.8269 \pm 0.0250$ & $0.8|40 \pm 0.023|$ & $<0.001$ \\
\hline FEVI LLN, L & $2.3 I \pm 0.53$ & $2.32 \pm 0.58$ & $<0.001$ \\
\hline Males & $2.59 \pm 0.41$ & $2.63 \pm 0.49$ & $<0.001$ \\
\hline Females & $1.91 \pm 0.40$ & $1.80 \pm 0.39$ & $<0.001$ \\
\hline FVC LLN, L & $2.80 \pm 0.62$ & $2.97 \pm 0.68$ & $<0.001$ \\
\hline Males & $3.21 \pm 0.39$ & $3.37 \pm 0.54$ & $<0.001$ \\
\hline Females & $2.24 \pm 0.39$ & $2.42 \pm 0.43$ & $<0.001$ \\
\hline FEVI/FVC LLN & $0.7465 \pm 0.0207$ & $0.7038 \pm 0.0312$ & $<0.001$ \\
\hline Males & $0.7394 \pm 0.0189$ & $0.6965 \pm 0.0305$ & $<0.001$ \\
\hline Females & $0.7565 \pm 0.0188$ & $0.7|4| \pm 0.029 \mid$ & $<0.001$ \\
\hline
\end{tabular}

Notes: The data was the predicted value and LLN of the participants. Data are presented as mean \pm standard deviation. Zhongshan-20II, the reference value published by Zhongshan hospital 20II.

Abbreviations: FEVI, forced expiratory volume in I s; FVC, forced vital capacity; GLI-2012, Global Lung Function Initiative 2012 equations; LLN, lower limits of normal; VC, vital capacity.
The Bland-Altman plot also showed that compared to GLI-2012, the Zhongshan-2011 underestimate the predicted value and LLN of FVC whereas predicted value and LLN of FEV1/FVC were overestimated in Zhongshan-2011 than in GLI-2012 (Figure 2).

\section{The Relationship Between Reference Values of FEVI/FVC and Age}

The relationship between reference values of FEV1/FVC and ages using Zhongshan-2011 and GLI-2012 was investigated. The predicted value of $\mathrm{FEV} 1 / \mathrm{FVC}$ was negatively correlated with ages $(\mathrm{R}=-0.7$ in Zhongshan2011 and $\mathrm{R}=-0.917$ in GLI-2012) at a significant level. We further investigated the age of the participants whose LLN of FEV1/FVC were lower than 0.7. Using GLI2012 of reference value, 27,893 (48.18\%) participants' LLN of FEV1/FVC were lower than 0.7 and only 113 $(0.20 \%)$ of the participants' LLN of FEV1/FVC were lower than 0.7 using Zhongshan-2011. The average age of those participants with an LLN of FEV1/FVC below 0.7 was $66.59 \pm 6.05$ using GLI-2012, which was significantly lower than that in Zhongshan-2011 (77.46 \pm 2.63 , $\mathrm{P}<0.001)$. The smallest age of LLN blow 0.7 was 52 in GLI-2012 whereas 70 in Zhongshan-2011.

\section{The Influence of Diagnostic Criteria on the Frequency of Airway Obstruction}

The frequency of airway obstruction using different diagnostic criteria: FEV1/FVC $<$ LLN or FEV1/FVC $<92 \%$ pred (Table 3) was compared. When Zhongshan-2011 was used as reference value, there was no significant difference in airway obstruction frequency between two diagnostic criteria in 18-44 age group (31.66\% vs $32.59 \%, \mathrm{P}=0.124$ ). However, in other age groups 

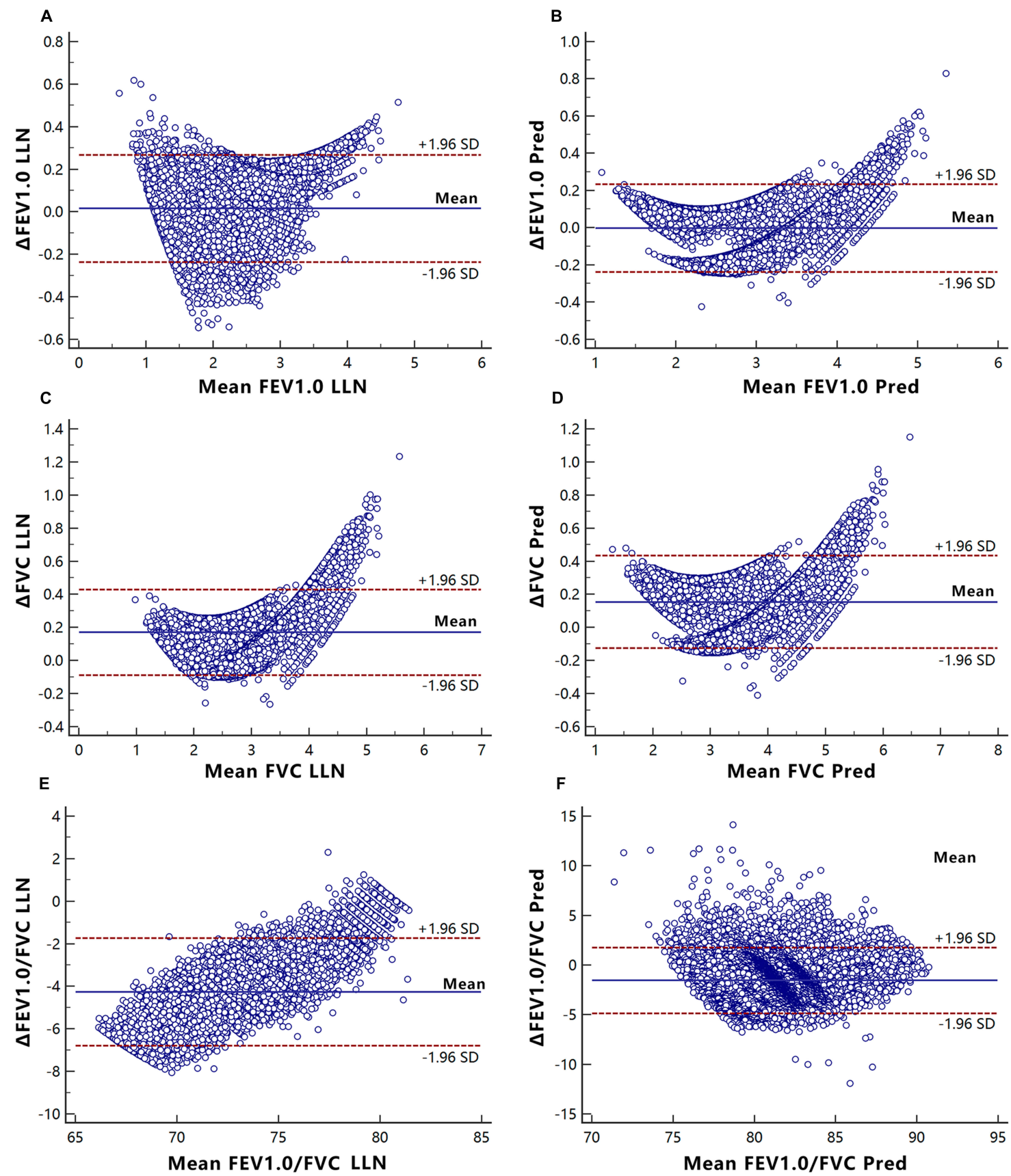

Figure 2 Bland-Altman spot of LLN and predicted values of GLI-20I2 and Zhongshan-20II.

Note: Zhongshan-20I I, the reference value published by Zhongshan hospital 20I I.Panels A, C and E illustrate the comparisons of LLN of FEVI, FVC and FEVI/FVC between GLI-20I 2 and Zhongshan-20I I; Panels B, D and F illustrate the comparisons of predicted values of FEVI, FVC and FEVI/FVC between GLI-20I2 and Zhongshan-20II. Abbreviations: $\Delta$, difference of GLI-20I2 data minus Zhongshan-20II data; FEVI, forced expiratory volume in I s; FVC, forced vital capacity; GLI-20I2, Global Lung Function Initiative 2012 equations; LLN, lower limits of normal.

(45-59 or 60-80), more participants were defined as obstructive using $\mathrm{FEV} 1 / \mathrm{FVC}<92 \%$ pred than $\mathrm{FEV} 1 / \mathrm{FVC}<\mathrm{LLN}$ $(\mathrm{P}<0.001)$. When GLI-2012 was used as reference value, there were more subjects defined as obstructive using FEV1/FVC $<92 \%$ pred than FEV1/FVC $<$ LLN $(\mathrm{P}<0.001)$ in all age groups.

\section{The Frequency of Airway Obstruction Using Different Reference Equations}

Using FEV1/FVC $<$ LLN as diagnostic criteria, more people were defined as obstructive according to Zhongshan2011 than GLI-2012 in each age group $(P<0.001)$. Among all the age groups, the $60-80$ age group showed the largest 
Table 3 The Influence of Diagnostic Criteria and Reference Equations on the Frequency of Airway Obstruction

\begin{tabular}{|c|c|c|c|c|c|c|c|}
\hline \multirow[t]{2}{*}{ Subjects, n(\%) } & \multirow[t]{2}{*}{ All } & \multicolumn{2}{|l|}{ Zhongshan-20II } & \multirow[t]{2}{*}{$\mathbf{P}$} & \multicolumn{2}{|l|}{ GLI-20I 2} & \multirow[t]{2}{*}{$\mathbf{P}$} \\
\hline & & FEVI/FVC <LLN & FEVI/FVC $<92 \%$ pred & & FEVI/FVC $<L L N$ & FEVI/FVC $<92 \%$ pred & \\
\hline All & 57,888 & $22,715(39.24 \%)$ & $23,874(41.24 \%)$ & $<0.001$ & $16,345(28.24 \%)$ & $21,076(36.41 \%)$ & $<0.001$ \\
\hline Age I8-44 & 12,134 & $3842(31.66 \%)$ & $3954(32.59 \%)$ & 0.124 & $2853(23.51 \%)$ & $3685(30.37 \%)$ & $<0.001$ \\
\hline Age 45-59 & 19,977 & $7761(38.85 \%)$ & $8088(40.49 \%)$ & $<0.001$ & $5644(28.25 \%)$ & $7067(35.38 \%)$ & $<0.001$ \\
\hline Age $60-80$ & 25,777 & II,II2(43.II\%) & II,832(45.90\%) & $<0.001$ & $7848(30.45 \%)$ & $10,324(40.05 \%)$ & $<0.001$ \\
\hline
\end{tabular}

Notes: Data are presented as $\mathrm{n}$ or $\mathrm{n}$ (\%). Zhongshan-20II, the reference value published by Zhongshan hospital in $20 \mathrm{II}$.

Abbreviations: FEVI, forced expiratory volume in I s; FVC, forced vital capacity; GLI-20I2, Global Lung Function Initiative 2012 equations; LLN, lower limits of normal.

difference in airway obstruction frequency between two reference equations ( $43.11 \%$ vs $30.45 \%, P<0.001)$. Using FEV1/FVC $<92 \%$ pred as diagnostic criteria produced similar results, more people were defined as obstructive according to Zhongshan-2011 than GLI-2012 in each age group $(P<0.001)$. The largest difference was also showed in $60-80$ age group $(45.90 \%$ vs $40.05 \%, P<0.001)$.

\section{The Diagnosis Concordance Rate} Between the Two Reference Equations

When using FEV1/FVC $<$ LLN as diagnostic criteria, the diagnosis concordance rate between the two reference equations was $88.99 \%(51,516 / 57,888)$ in all the participants, $91.83 \%(11,143 / 12,134)$ in $18-44$ age group, $89.40 \%(17,860 / 19,977)$ in $45-59$ age group, $84.34 \%$ $(22,513 / 25,777)$ in $60-80$ age group (Table 4$)$. When using $\mathrm{FEV} 1 / \mathrm{FVC}<92 \%$ pred as diagnostic criteria, the diagnosis concordance rate was $94.20 \%(54,530 / 57,888)$ in all participants, $95.39 \%(11,575 / 12,134)$ in $18-44$ age group, $94.10 \%(18,798 / 19,977)$ in $45-59$ age group and $93.72 \%(24,157 / 25,777)$ in $60-80$ age group (Table 5$)$.

\section{Discussion}

In this study, we investigated the influence of diagnostic criteria and reference equations in the diagnosis of airway obstruction in adult Chinese. There were significant differences between the two reference equations (GLI-2012 and Zhongshan-2011). The Zhongshan-2011 identified more obstructive subjects than GLI-2012. Different diagnostic criteria can also influence the frequency of airway obstruction.

The reference equations are the basis for the interpretation of PFT. To the extent of the authors' knowledge, there are still no reports comparing the applicability between Zhongshan-2011 and GLI-2012 in adult people of North China. In this study, a large sample of adult people who underwent PFTs in a teaching hospital of North China was
Table 4 Numbers of Concordant and Discordant Pairs When Using FEVI/FVC $<$ LLN as Diagnostic Criterion Between GLI2012 and Zhongshan-20II to Diagnose Airway Obstruction

\begin{tabular}{|c|c|c|c|}
\hline \multirow[t]{2}{*}{ Subjects, n(\%) } & \multicolumn{2}{|l|}{ GLI-20I 2} & \multirow[t]{2}{*}{ Total } \\
\hline & No & Yes & \\
\hline \multicolumn{4}{|l|}{ All } \\
\hline \multicolumn{4}{|l|}{ Zhongshan-20II } \\
\hline No & 35,172 (60.76\%) & I (0.00\%) & 35,173 \\
\hline Yes & 6371 (11.01\%) & 16,344 (28.23\%) & 22,715 \\
\hline Total & $4 I, 543$ & 16,345 & 57,888 \\
\hline \multicolumn{4}{|l|}{ Age 18-44 } \\
\hline \multicolumn{4}{|l|}{ Zhongshan-20II } \\
\hline No & 8291 (68.33\%) & $\mathrm{I}(0.01 \%)$ & 8292 \\
\hline Yes & 990 (8.16\%) & 2852 (23.50\%) & 3842 \\
\hline Total & 9281 & 2853 & 12,134 \\
\hline \multicolumn{4}{|l|}{ Age $45-59$} \\
\hline \multicolumn{4}{|l|}{ Zhongshan-20II } \\
\hline No & 12,216 (6I.15\%) & $0(0.00 \%)$ & 12,216 \\
\hline Yes & 2117 (10.60\%) & $5644(28.25 \%)$ & 7761 \\
\hline Total & 14,333 & 5644 & 19,977 \\
\hline \multicolumn{4}{|l|}{ Age $60-80$} \\
\hline \multicolumn{4}{|l|}{ Zhongshan-20II } \\
\hline No & I4,665 (56.89\%) & $0(0.00 \%)$ & 14,665 \\
\hline Yes & 3264 (I2.66\%) & 7848 (30.45\%) & 11,112 \\
\hline Total & 17,929 & 7848 & 25,777 \\
\hline
\end{tabular}

Note: Data are presented as $\mathrm{n}$ or $\mathrm{n}(\%)$.

Abbreviations: FEVI, forced expiratory volume in I s; FVC, forced vital capacity; GLI20I2, Global Lung Function Initiative 2012 equations; LLN, lower limits of normal.

enrolled. The results of this study showed that there were significant differences between the two reference equations in FEV1/FVC. The predicted value and LLN of FEV1/FVC in GLI-2012 were significantly lower than that in Zhongshan-2011. One possible reason is that two versions of reference equations were obtained from differently recruited "normal" or "healthy" subjects. This result indicated that adult people are more likely to be diagnosed with airway obstruction when the Zhongshan-2011 rather than GLI-2012 is used. 
Table 5 Numbers of Concordant and Discordant Pairs When Using FEVI/FVC $<92 \%$ Pred as Diagnostic Criterion Between GLI-20I 2 and Zhongshan-20II to Diagnose Airway Obstruction

\begin{tabular}{|c|c|c|c|}
\hline \multirow[t]{2}{*}{ Subjects, n(\%) } & \multicolumn{2}{|l|}{ GLI2-012 } & \multirow[t]{2}{*}{ Total } \\
\hline & No & Yes & \\
\hline \multicolumn{4}{|l|}{ All } \\
\hline \multicolumn{4}{|l|}{ Zhongshan-20II } \\
\hline No & 33,734 (58.27\%) & $280(0.04 \%)$ & 34,014 \\
\hline Yes & 3078 (5.32\%) & 20,796 (35.92\%) & 23,874 \\
\hline Total & 36,812 & 21,076 & 57,888 \\
\hline \multicolumn{4}{|l|}{ Age 18-44 } \\
\hline \multicolumn{4}{|l|}{ Zhongshan-20II } \\
\hline No & 8035 (66.22\%) & 145 (1.19\%) & 8180 \\
\hline Yes & 414 (3.4I\%) & $3540(29.17 \%)$ & 3954 \\
\hline Total & 8449 & 3685 & 12,134 \\
\hline \multicolumn{4}{|l|}{ Age $45-59$} \\
\hline \multicolumn{4}{|l|}{ Zhongshan-20II } \\
\hline No & II,8I0 (59.12\%) & 79 (0.39\%) & 11,889 \\
\hline Yes & 1100 (5.5I\%) & 6988 (34.98\%) & 8088 \\
\hline Total & 12,910 & 7067 & 19,977 \\
\hline \multicolumn{4}{|l|}{ Age $60-80$} \\
\hline \multicolumn{4}{|l|}{ Zhongshan-20II } \\
\hline No & I3,889 (53.88\%) & $56(0.22 \%)$ & 13,945 \\
\hline Yes & 1564 (6.07\%) & $10,268(39.83 \%)$ & 11,832 \\
\hline Total & 15,453 & 10,324 & 25,777 \\
\hline
\end{tabular}

Note: Data are presented as $\mathrm{n}$ or $\mathrm{n}(\%)$.

Abbreviations: FEVI, forced expiratory volume in I s; FVC, forced vital capacity; GLI-20I2, Global Lung Function Initiative 2012 equations.

The FEV1/FVC of normal population declined with the increase of ages. Our results also proved that the reference values of FEV1/FVC decreased with ages. However, the average age of those participants who had an LLN of FEV1/FVC below 0.7 was significantly lower in GLI2012 than that in Zhongshan-2011. A previous US study proved that, in Caucasians, the difference between different reference equations in LLN of FEV1/FVC might be influenced by height and age. ${ }^{18}$ Both of the two versions have the average age at which the LLN of FEV1/FVC fall below 0.70 is over 60 years, which is older than the results of a previous study (42 and 48 years in males and females). ${ }^{19}$ This may be due to differences in the race of study populations. More people were defined as obstructive according to Zhongshan-2011 than GLI-2012, especially in old people.

Beside the reference equations, the criterion for airway obstruction definition also has a large impact on the diagnosis of airway obstruction. ${ }^{20-22}$ The FEV1/FVC $<$ LLN was the most widely used diagnostic criteria for airway obstruction. However, because the calculation of LLN was relatively complex, the usage of LLN in clinical practices was limited. In that case, some scholars proposed to use FEV1/FVC or FEV1/vital capacity (VC) lower than the percentage of predicted value as a surrogate diagnostic criteria. ${ }^{4,23}$ For instance, the consensus statement of ERS on COPD in 1995 recommended FEV1/VC $<88 \%$ predicted in males or $<89 \%$ predicted in females as the diagnostic criteria of airway obstruction. ${ }^{23} \mathrm{FEV} 1 / \mathrm{FVC}<92 \%$ predicted has also been recommended by the Chinese guideline of PFT, ${ }^{5}$ but there is still a lack of studies to confirm the accuracy of these diagnostic criteria. The results show that FEV1/FVC $<92 \%$ pred identified more airway obstruction than $\mathrm{FEV} 1 / \mathrm{FVC}<\mathrm{LLN}$ in people older than 45 , especially in $60-80$ age group. This indicates that FEV1/FVC $<92 \%$ pred may lead to overdiagnosis of airway obstruction in elderly people compared to LLN. The difference between the two diagnostic criteria was larger when using GLI-2012, which indicated the accuracy of $\mathrm{FEV} 1 / \mathrm{FVC}<92 \%$ pred might be influenced by different reference equations.

We further investigated the diagnostic concordance between two reference equations in different age groups. When using FEV1/FVC $<\mathrm{LLN}$ as diagnostic criteria, the diagnosis concordance rate between the two reference equations was $88.99 \%$, which was lower than that of using FEV1/ FVC $<92 \%$ pred as diagnostic criteria (94.20\%, p $<0.001$ ). When FEV1/FVC $<\mathrm{LLN}$ as diagnostic criteria, the diagnosis concordance rate between the two reference equations in 60-80 group was lower than younger groups.

In recent years, the $\mathrm{z}$-score has been recommended as an evaluating index for spirometry parameters. ${ }^{8} \mathrm{Z}$-scores indicate how many standard deviations a measurement is from its predicted value. However, the Zhongshan-2011 has no z-score equations of spirometry parameters. In addition, the statistical value of $z$-score $(-1.64)$ was equal to LLN at the 5 th centile. ${ }^{8}$ In order to compare between these two reference equations, we chose to use LLN but not z-score. In this study, we only based on the PFTs to determine airway obstruction. But in clinical practice, other factors including symptoms and chest imaging should also be considered, especially for patients near cut-off values.

The GOLD guideline uses post-bronchodilator FEV1/ FVC $<0.7$ as the diagnostic criteria of airflow limitation. ${ }^{6}$ Because the fixed cut-off value of FEV1/FVC is simple and its value on the diagnosis and treatment of COPD has been verified in numerous clinical trials, some hospitals in China use GOLD criterion to define the airway obstruction. ${ }^{24-29}$ However, previous studies proved that using a fixed 
FEV1/FVC ratio may result in a significant number of falsepositive results in old people. ${ }^{30,31}$ In addition, GOLD criterion for COPD is defined by a post-bronchodilator FEV1/FVC $<0.7$, which may not suitable for pre-bronchodilator estimation of airway obstruction. So the GOLD criterion was not enrolled in this study.

The fitness of GLI-2012 and Zhongshan-2011 in North China has not been fully illustrated. The results of this study showed that only $0.20 \%$ of the participants' LLN of FEV1/FVC using Zhongshan-2011 were lower than 0.7, which indicated that FEV1/FVC was overestimated in Zhongshan-2011. In our previous study, we proved that the LLN of FEV1/FVC of GLI-2012 was lower than normal people aged 60-84 years old in Jinan, a city with more than 7 million people in North China. ${ }^{32}$ So both Zhongshan-2011 and GLI-2011 may not be the most appropriate reference equations for the adult people of North China.

Our study has several limitations. First, this was a retrospective study and only those who underwent PFTs in hospital were enrolled, and the age was limited from 18 to 80 . These might lead to possible selection bias. In the future, we will make a further study on the community population of Chinese with a wider range of ages. Second, the fitness of the reference equations and diagnostic criteria for healthy people had not been investigated.

\section{Conclusion}

In conclusion, the predicted value of GLI-2012 and Zhongshan-2011 differs significantly. The Zhongshan2011 identifies more obstructive subjects than GLI-2012 in each age group of adult people of North China. The influence of diagnostic criteria on the frequency of airway obstruction related with reference equations and age groups. Compared to LLN, FEV1/FVC < $<2 \%$ pred may lead to overdiagnosis of airway obstruction in elderly people.

\section{Acknowledgments}

This work was supported by grants from the National Key Research and Development Program in China [grant number 2016YFC0903603].

\section{Disclosure}

The authors report no conflicts of interest in this work.

\section{References}

1. Rogliani P, Ora J, Puxeddu E, Cazzola M. Airflow obstruction: is it asthma or is it COPD? Int $J$ Chron Obstruct Pulmon Dis. 2016;11:3007-3013. doi:10.2147/COPD

2. Hogg JC, McDonough JE, Suzuki M. Small airway obstruction in COPD. Chest. 2013;143(5):1436-1443. doi:10.1378/chest.12-1766

3. Crapo RO. Pulmonary-function testing. $N$ Engl J Med. 1994;331 (1):25-30. doi:10.1056/NEJM199407073310107

4. Pellegrino R. Interpretative strategies for lung function tests. Eur Respir J. 2005;26(5):948-968. doi:10.1183/09031936.05.00035205

5. Group SPFT. Guidelines for pulmonary function tests. Chin J Tubere Respir Dis. 2014(7). 487-491. doi: 10.3760/cma.j.issn.10010939.2014.07.002)

6. GOLD. Global initiative for chronic obstructive lung disease, global strategy for the diagnosis, management and prevention of COPD 2017. [updated 2017; cited 2011]. Available from: https://goldcopd. org/gold-2017-global-strategy-diagnosis-management-preventioncopd/. Accessed March 17, 2020.

7. Ren WY, Zhu L, Zhao RY, et al. Preliminary study on medical reference range for adult pulmonary function parameters in Shanghai. Chin J Respir Crit Care Med. 2012;11(3):253-256.

8. Quanjer PH, Stanojevic S, Cole TJ, et al. Multi-ethnic reference values for spirometry for the $3-95-y r$ age range: the global lung function 2012 equations. Eur Respir J. 2012;40(6):1324-1343. doi:10.1183/09031936.00080312

9. Langhammer A, Johannessen A, Holmen TL, et al. Global lung function initiative 2012 reference equations for spirometry in the Norwegian population. Eur Respir J. 2016;48(6):1602-1611. doi:10.1183/13993003.00443-2016

10. Hüls A, Krämer U, Stolz S, et al. Applicability of the global lung initiative 2012 reference values for spirometry for longitudinal data of elderly women. PLoS One. 2016;11(6):e157569. doi:10.1371/journal.pone. 0157569

11. Arigliani M, Canciani MC, Mottini G, et al. Evaluation of the global lung initiative 2012 reference values for spirometry in African children. Am J Resp Crit Care. 2017;195(2):229-236. doi:10.1164/ rccm.201604-0693OC

12. Slattery F, Schermer T, Esterman A, Johnston K, Crockett A. The global lung function initiative 2012 equations are as well-suited as local population derived equations to a sample of healthy professional firefighters. Can Respir J. 2017;2017:1-6. doi:10.1155/2017/ 6327180

13. Backman H, Lindberg A, Sovijärvi A, Larsson K, Lundbäck B, Rönmark E. Evaluation of the global lung function initiative 2012 reference values for spirometry in a Swedish population sample. BMC Pulm Med. 2015;15(1). doi:10.1186/s12890-015-0022-2

14. Fasola S, La Grutta S, Cibella F, Cilluffo G, Viegi G. Global lung function initiative 2012 reference values for spirometry in South Italian children. Resp Med. 2017;131:11-17. doi:10.1016/j. rmed.2017.07.061

15. World Medical Association. World medical association declaration of Helsinki: ethical principles for medical research involving human subjects. JAMA. 2013;310(20):2191-2194. doi: 10.1001/jama.2013. 281053.

16. Miller MR. Standardisation of spirometry. Eur Respir J. 2005;26 (2):319-338. doi:10.1183/09031936.05.00034805

17. Shibuya K, Mathers CD, Boschi-Pinto C, Lopez AD, Murray CJ. Global and regional estimates of cancer mortality and incidence by site: II. Results for the global burden of disease 2000. BMC Cancer. 2002;2(1):37. doi:10.1186/1471-2407-2-37

18. Linares-Perdomo O, Hegewald M, Collingridge DS, et al. Comparison of NHANES III and ERS/GLI-2012 for airway obstruction classification and severity. Eur Respir J. 2016;48(1):133-141. doi:10.1183/13993003.01711-2015 
19. Swanney MP, Ruppel G, Enright PL, et al. Using the lower limit of normal for the FEV1/FVC ratio reduces the misclassification of airway obstruction. Thorax. 2008;63(12):1046-1051. doi:10.1136/ thx.2008.098483

20. Viegi G, Pedreschi M, Pistelli F, et al. Prevalence of airways obstruction in a general population. Chest. 2000;117(5suppl 2):339S-345S.

21. Andreeva E, Pokhaznikova M, Lebedev A, Moiseeva I, Kutznetsova O, Degryse J. The prevalence of chronic obstructive pulmonary disease by the global lung initiative equations in north-western Russia. Respiration. 2016;91(1):43-55. doi:10.1159/ 000442887

22. Vaz Fragoso CA, McAvay G, Van Ness PH, et al. Phenotype of normal spirometry in an aging population. Am J Resp Crit Care. 2015;192(7):817-825. doi:10.1164/rccm.201503-0463OC

23. Siafakas NM, Vermeire P, Pride NB, et al. Optimal assessment and management of chronic obstructive pulmonary disease (COPD). Eur Respir J. 1995;8(8):1398-1420. doi:10.1183/09031936.95.08 081398

24. Vogelmeier C, Hederer B, Glaab T, et al. Tiotropium versus salmeterol for the prevention of exacerbations of COPD. New Engl J Med. 2011;364(12):1093. doi:10.1056/NEJMoa1008378

25. Singh D, Papi A, Corradi M, et al. Single inhaler triple therapy versus inhaled corticosteroid plus long-acting $\beta 2$-agonist therapy for chronic obstructive pulmonary disease (TRILOGY): a double-blind, parallel group, randomised controlled trial. Lancet. 2016;388(10048):963. doi:10.1016/S0140-6736(16)31354-X
26. Wedzicha JA, Banerji D, Chapman KR, et al. Indacaterolglycopyrronium versus salmeterol-fluticasone for COPD. New Engl $J$ Med. 2016;374(23):2222. doi:10.1056/NEJMoa1516385

27. Vestbo J, Anderson JA, Brook RD, et al. Fluticasone furoate and vilanterol and survival in chronic obstructive pulmonary disease with heightened cardiovascular risk (SUMMIT): a double-blind randomised controlled trial. Lancet. 2016;387(10030):1817. doi:10.1016/ S0140-6736(16)30069-1

28. Decramer M, Celli B, Kesten S, et al. Effect of tiotropium on outcomes in patients with moderate chronic obstructive pulmonary disease (UPLIFT): a prespecified subgroup analysis of a randomised controlled trial. Lancet. 2009;374(9696):1171-1178. doi:10.1016/ S0140-6736(09)61298-8

29. Tashkin DP, Celli B, Senn S. A 4-year trial of tiotropium in chronic obstructive pulmonary disease - NEJM. N Engl J Med. 2008;359 (15):1543-1554. doi:10.1056/NEJMoa0805800

30. Hardie JA, Buist AS, Vollmer WM, Ellingsen I, Bakke PS, Morkve O. Risk of over-diagnosis of COPD in asymptomatic elderly never-smokers. Eur Respir J. 2002;20(5):1117-1122. doi:10.1183/ 09031936.02 .00023202

31. Medbø A, Melbye H. Lung function testing in the elderly-Can we still use FEV1/FVC $<70 \%$ as a criterion of COPD? Resp Med. 2007;101(6):1097-1105.

32. Tian XY, Liu CH, Wang DX, et al. Spirometric reference equations for elderly Chinese in Jinan aged 60-84 years. Chin Med J (Engl). 2018;131(9):1016-1022. doi:10.4103/0366-6999.227840

\section{Publish your work in this journal}

The International Journal of COPD is an international, peer-reviewed journal of therapeutics and pharmacology focusing on concise rapid reporting of clinical studies and reviews in COPD. Special focus is given to the pathophysiological processes underlying the disease, intervention programs, patient focused education, and self management protocols. This journal is indexed on PubMed Central, MedLine and CAS. The manuscript management system is completely online and includes a very quick and fair peer-review system, which is all easy to use. Visit http://www.dovepress.com/testimonials.php to read real quotes from published authors. 